\title{
Structural Study of Porous Si with Different Crystal Orientation Fabricated Using Two-Step Alternating Current Photo-Electrochemical Etching Technique
}

\author{
Fatimah Zulkifli, Rosfariza Radzali, Alhan Farhanah Abd Rahim, Ainorkhilah Mahmood and Aslina \\ Abu Bakar
}

\begin{abstract}
Two different crystal orientation of n-type Si substrates $n(100)$ and $n(111)$ were used to fabricate porous structure using two-step Alternating Current PhotoElectrochemical (ACPEC) etching technique. This research aims to investigate the difference of porous structure and properties for different orientation of n-type Si substrate. In this work, before alternating current (AC) was supplied, the samples were immensed in HF: Ethanol for 10 minutes. Then, each sample were etched at $20 \mathrm{~mA} / \mathrm{cm}^{2}$ current density for 30 minutes. The porous Si samples were then characterized for Field Emission Scanning Electron Microscopy (FESEM), Atomic Force Microscopy (AFM) and High Resolution X-ray Diffraction (HR-XRD) to study the surface morphology of the samples. The results obtained showed that porous Si with orientation of (100) has higher pore density formation, higher surface roughness value in RMS and deeper pore depth with improved crystalline quality compared to Si with orientation of (111).
\end{abstract}

Index Terms-Alternating Current, Crystal Orientation, Electrochemical Etching, Porous Si.

\section{INTRODUCTION}

$\mathrm{S}_{\mathrm{a} a \mathrm{in}}^{\mathrm{n}}$ ILICON ( $\mathrm{Si}$ ) is the second abundant material after carbon and is widely used in semiconductor technology. The discovery of porous Si efficient visible luminescence at room temperature has garnered many attentions from researchers $[1$, 2]. Numerous electronic devices, ranging from optoelectronic to chemical and biochemical sensors applications, have been developed using porous $\mathrm{Si}$ due to its unique features such as high surface area, band gap shift, and efficient luminescence properties [3-7]. Solar cells [8, 9] and hydrogen gas sensing [6] are some of the few examples of application built using porous

This manuscript is submitted on $11^{\text {th }}$ May 2021 and accepted on $24^{\text {th }}$ August 2021. This work is supported financially by Ministry of Higher Education Malaysia (MOHE) through Fundamental Research Grant Scheme (600-RMI/FRGS 5/3(0107/2016).

F. Zulkifli, R. Radzali, A. F. A. Rahim, and A.A. Bakar are from School of Electrical Engineering, College of Engineering, Universiti Teknologi MARA, Cawangan Pulau Pinang, Kampus Permatang Pauh, 13500 Permatang Pauh, Pulau Pinang, Malaysia. A. Mahmood is from Department of Applied Sciences, Universiti Teknologi MARA, Cawangan Pulau Pinang, 13500 Permatang Pauh, Pulau Pinang, Malaysia (e-mail: rosfariza074@uitm.edu.my).

1985-5389/@ 2021 The Authors. Published by UiTM Press. This is an open access article under the CC BY-NC-ND license (http://creativecommons.org /licenses/by-nc-nd/4.0/).
Si. Photo-electrochemical (PEC) etching technique is an etching technique which uses a current supply, either direct current (DC) or alternating current (AC), along with the help of light source. This technique has its own advantages such as lowprocessing temperature, low structural damage, simple andversatile, and low cost compared to other technique available [10]. By varying the etching parameters such as etching duration and current density $[5,11-13]$, the porosity formation is more or less can be easily controlled.

In this work, two different crystal orientation of n-type $\mathrm{Si}$ which are $n(100)$ and $n(111)$ were used to fabricate porous structure using two-step Alternating Current PhotoElectrochemical (ACPEC) etching technique. The effect of different orientation of $\mathrm{Si}$ substrate towards the formation and properties of porous structure were investigate.

\section{EXPERIMENTAL PROCEDURE}

Two types of N-stype silicon substrates were used to fabricate porous sample in this research, namely $\mathrm{n}(100)$ and $\mathrm{n}(111)$. The techniques used to fabricate these samples is called two-steps ACPEC etching technique. Silicon wafer of both typewere cut into smaller pieces approximately $1 \mathrm{~cm} \times 1 \mathrm{~cm}$ to fit inthe Teflon cell. Then, Radio Corporation of America (RCA) cleaning method was used to clean the sample from any impurities before the etching process. It was important to ensure the sample was clean as the impurities could affect the etchingprocess and ruin the results obtained from the sample.

Fig. 1 shows the experimental setup. A Teflon cell with Oring and metal plate was used to hold the sample for etching process. The metal plate acted as anode during the process while platinum wire which was dipped into the electrolyte solution acted as cathode. The Si sample was fixed in between O-ring and metal plate with the front side was exposed to the electrolyte solution. The electrolyte solution used in this research was a mixture of hydrofluoric acid and ethanol with ratio of 1:4. This solution has been commonly used to fabricateporous silicon by other research groups $[5,14,15]$. Ethanol was used in the electrolyte solution to act as a surface-active agent which help to reduce surface tension during the etching processto achieve high density pore formation [16]. The ammeter was used to monitor the current supply. 
Two-steps ACPEC etching technique consist of two etching steps. The first step was to immerse the Si sample in electrolyte solution for a period of time to form a high density of etch pits [17]. The second step was to anodize the sample in electrolyte solution by supplying alternating current (AC) with current density of $20 \mathrm{~mA} / \mathrm{cm}^{2}$ for 30 minutes under the illumination of incandescent light [14]. Anodization using AC help to reduce the hydrogen bubbles and allow the HF to react with the $\mathrm{Si}$ surface [17]. Once etching process was done, the samples were rinsed with DI water and dry under ambient air.

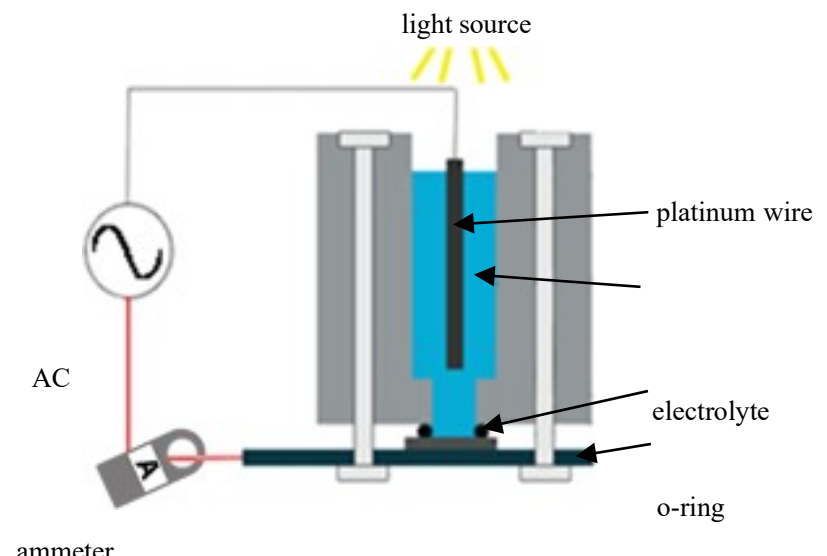

ammeter

metal plate

Fig. 1. Experimental setup for photo-electrochemical etching to fabricate porous $\mathrm{Si}$

All of the etched samples were characterized for their structural properties using Field Emission Scanning Electron Microscopy (FESEM) (Model: Jeol JSM 7401F), Atomic Force Microscopy (AFM) (Model: Dimension EDGE, BRUKER), and High Resolution X-ray Diffraction (HR-XRD) (Model: PANalytical X'pert Pro MRD).

\section{RESULTS AND DISCUSSIONS}

\section{A. Fields Emission Scanning Electron Microscopy Analysis}

Fig. 2 shows the FESEM images of as grown and porous $\mathrm{Si}$ sample with different crystal orientation. ImageJ software was utilized to examine the average pore size and porosity for each samples.

Fig. 2(a) and (c) show the surface morphology of as grown Si n(100) sample and Si n(111). Both images showed that the surface were very smooth with no pores or crack present. From Fig. 2(b) and (d), it can be seen that the formation of porous structure on Si n(100) sample was more uniform compared to porous structure on Si $\mathrm{n}(111)$ as there were less formation of pores can be seen for porous $\mathrm{Sin}$ (111) sample. On top of that, porous Si n(100) was observed to has higher density of porous structure compared to porous Si n(111) sample. Similar result obtained by Abd Wahab et al. where Si n(100) formed more uniform circular pore structure and dense compared to Si n(111) [18]. The shape of pores that formed on porous $\mathrm{Sin}(100)$ were mostly crisscross in shape with some of them contain square shape pores in the middle of the crisscross pores. Meanwhile, the shape of pores that formed on porous Si n(111) sample were mostly irregular with circle and square like pores. The pore length $(L)$, width $(W)$ and diameter $(D)$ were measured as indicated in the inset image of Fig. 2. The pore length is the length of the pore and the pore width is width of pore from the crisscross shaped pore. While, the pore diameter is the diameter of either the circular or square shaped pore. The average length of pores for porous $\mathrm{Si} \mathrm{n}(100)$ sample was $\sim 3.18 \mu \mathrm{m}$ with average width of $\sim 0.45 \mu \mathrm{m}$ and average diameter of the square shaped pores was $\sim 0.62 \mu \mathrm{m}$. As for porous Si n(111) sample, the average diameter of the irregular shaped pores was $\sim 0.73$ $\mu \mathrm{m}$.

From Fig. 2, the estimation of porosity percentage for each sample was determined using ImageJ by a proportion of sample surface involved with pores to the entire surface of the sample [19]. It can be seen that sample porous Si n(100) sample has higher porosity percentage compared to sample porous $\mathrm{Si}$ $\mathrm{n}(111)$ sample which are $24.43 \%$ and $16.88 \%$, respectively. The lower porosity percentage of sample $\mathrm{Si} \mathrm{n}(111)$ compared to $\mathrm{Si}$ $\mathrm{n}(100)$ was due to lower etching rate of Si $\mathrm{n}(111)$. The lower
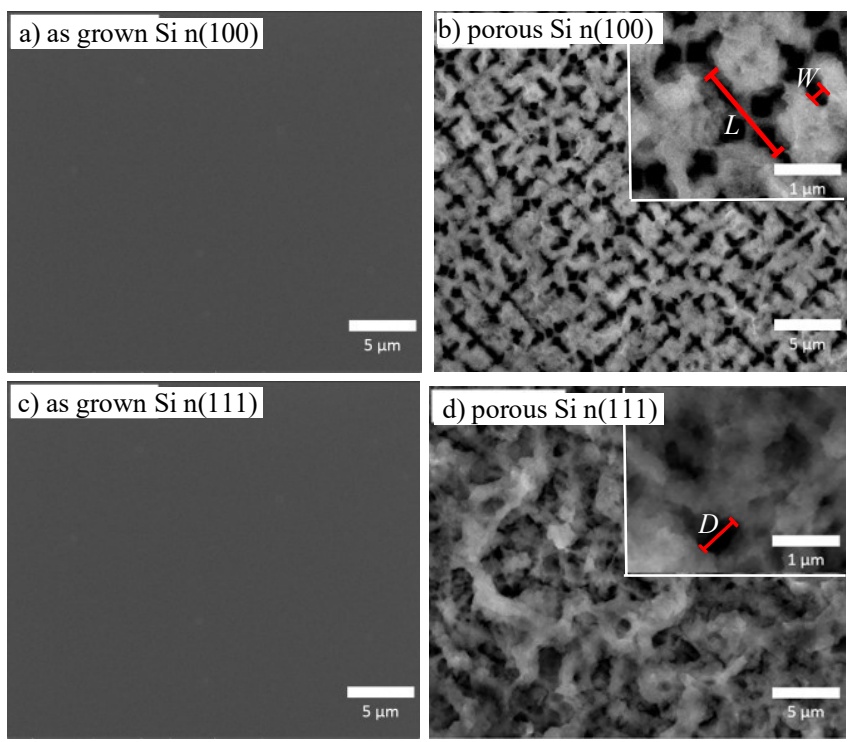

Fig. 2. Structures of as grown and porous Si samples with different orientation (a) as grown $\mathrm{Si}$ n(100), (b) porous $\mathrm{Si} \mathrm{n}(100)$, (c) as grown $\mathrm{n}(111)$ and (d) porous $\operatorname{Sin}(111)$.

TABLE I

SUMMARY OF POROSITY AND PORE SIZE FOR POROUS SI N(100) AND N(111)

\begin{tabular}{|c|c|c|c|c|}
\hline Sample & $\begin{array}{c}\text { Averag } \\
\text { ePore } \\
\text { Length }\end{array}$ & $\begin{array}{c}\text { Average } \\
\text { Pore } \\
\text { Width }(\mu \mathrm{m})\end{array}$ & $\begin{array}{c}\text { Average } \\
\text { Pore } \\
\text { Diamete } \\
\mathrm{r} \\
(\mu \mathrm{m})\end{array}$ & $\begin{array}{c}\text { Estimate } \\
\text { dPorosity } \\
(\%)\end{array}$ \\
\hline PSi n(100) & 3.18 & 0.45 & 0.62 & 24.43 \\
\hline PSi n(111) & 0.73 & 2.05 & 0.37 & 16.88 \\
\hline
\end{tabular}

etching rate for $\mathrm{Sin}(111)$ could be related to its atomic structure which was densely packed compared to Si n(100) [20,21]. On top of that, the lower etching rate of $\mathrm{Sin}$ (111) is also probably due to the energy required to remove atoms from the surface was relatively much higher in Si n(111) compared to Si n(100). This is because each atom of $\mathrm{Sin}$ (111) surface has one dangling bond and three back bonds while each atom of Si n(100) surface has two dangling bond and two back bonds only. Therefore, the 
activation energy to remove an atom from the surface of $\mathrm{Si}$ $\mathrm{n}(111)$ is higher which it needs to break three back bonds compared to only two back bonds in the case of $\mathrm{Si} \mathrm{n}(100)$ surface $[20,21]$. Based on these results, it can be concluded that pore formation was better on sample Si n(100) compared to sample Si n(111). Therefore, FESEM results indicated that $\mathrm{Si}$ $\mathrm{n}(100)$ was more suitable to fabricate porous structure with high density and uniformity pores. Table I shows the summary of pore size for each porous sample with their respective porosity.

\section{B. Atomic Force Microscopy Analysis}

Fig. 3 shows the AFM measurement of as grown and porousSi sample with different orientation. The average surface roughness in root mean square (RMS) was determined using the

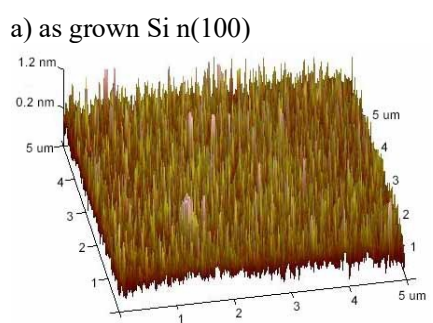

c) as grown $\operatorname{Sin}(111)$

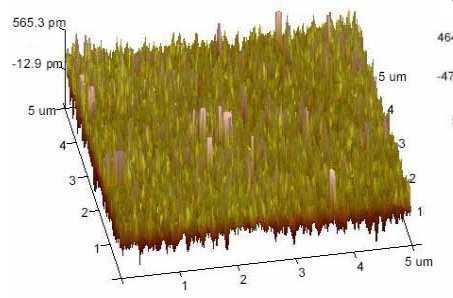

b) porous $\mathrm{Sin}(100)$

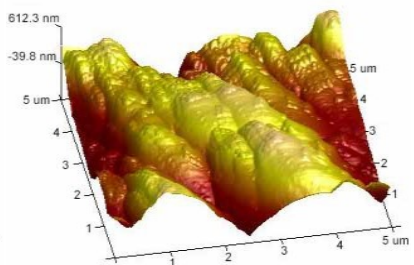

d) porous $\operatorname{Sin}(111)$

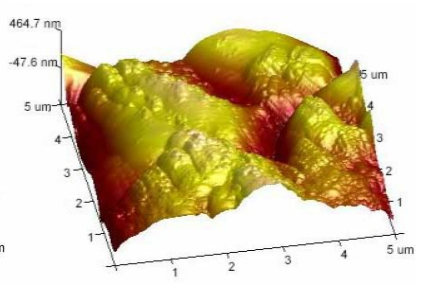

Fig. 3. AFM measurement of as grown and porous Si samples with different orientation (a) as grown $\mathrm{n}(100)$, (b) porous $\mathrm{Si} \mathrm{n}(100)$, (c) as grown $\mathrm{n}(111)$ and (d) porous Si n(111).

TABLE II

SUMMARY OF AFM MEASUREMENT OF AS GROWN SI N(100), POROUS SI N(100), AS GROWN SI N(111) AND POROUS SI N(111)

\begin{tabular}{|c|c|c|}
\hline \multicolumn{1}{|c|}{ Sample } & $\begin{array}{c}\text { Average Pore Depth } \\
(\mathrm{nm})\end{array}$ & $\begin{array}{c}\text { Surface Roughness in } \\
\text { RMS (nm) }\end{array}$ \\
\hline As grown Si n(100) & 0.262 & 0.296 \\
\hline Porous Si n(100) & 260.832 & 215.0 \\
\hline As grown Si n(111) & 0.213 & 0.194 \\
\hline Porous Si n(111) & 86.775 & 161.0 \\
\hline
\end{tabular}

NanoScope Analysis Software and estimated pore depth of each sample were determined using the line scan. The data obtained was calculated and tabulated in Table II.

The low surface roughness of as grown Si n(100) and n(111) with RMS value of $0.30 \mathrm{~nm}$ and $0.19 \mathrm{~nm}$, respectively showed the absence of pores on the surface. On the other hand, porous Si n(100) and $\mathrm{n}(111)$ samples have higher RMS value compared to as grown sample, thus showing that there were pores present on the surface as the structure of the porous samples have been altered during the etching process [22].

The AFM results also shows that porous Si $\mathrm{n}(100)$ sample has higher average pore depth of $\sim 260.83 \mathrm{~nm}$ compared to average pore depth of porous $\operatorname{Sin} \mathrm{n}(111)$ which was $\sim 86.78 \mathrm{~nm}$. This result is supported by FESEM images in Fig. 2(b) where porous Si $\mathrm{n}(100)$ showed deeper pores (visible as darker area) compared to porous Si n(111) in Fig. 2(d). Porous Si n(100) also has higher RMS value which was $215.0 \mathrm{~nm}$ compared to porous Si n(111) which has RMS value of $161.0 \mathrm{~nm}$. The lower surface roughness of $\mathrm{Si} \mathrm{n}(111)$ was associated to its lower etch rate compared to $\operatorname{Sin}(100)[20,21]$ as explained previously. Similar results were observed from previous research where $\mathrm{Si}$ n(100) sample has higher RMS value compared to Si $\mathrm{n}(111)$ sample [18]. Therefore, porous $\mathrm{Si} n(100)$ sample has more pores formed compared to porous Si $\mathrm{n}(111)$ that has widely spread pores formation.
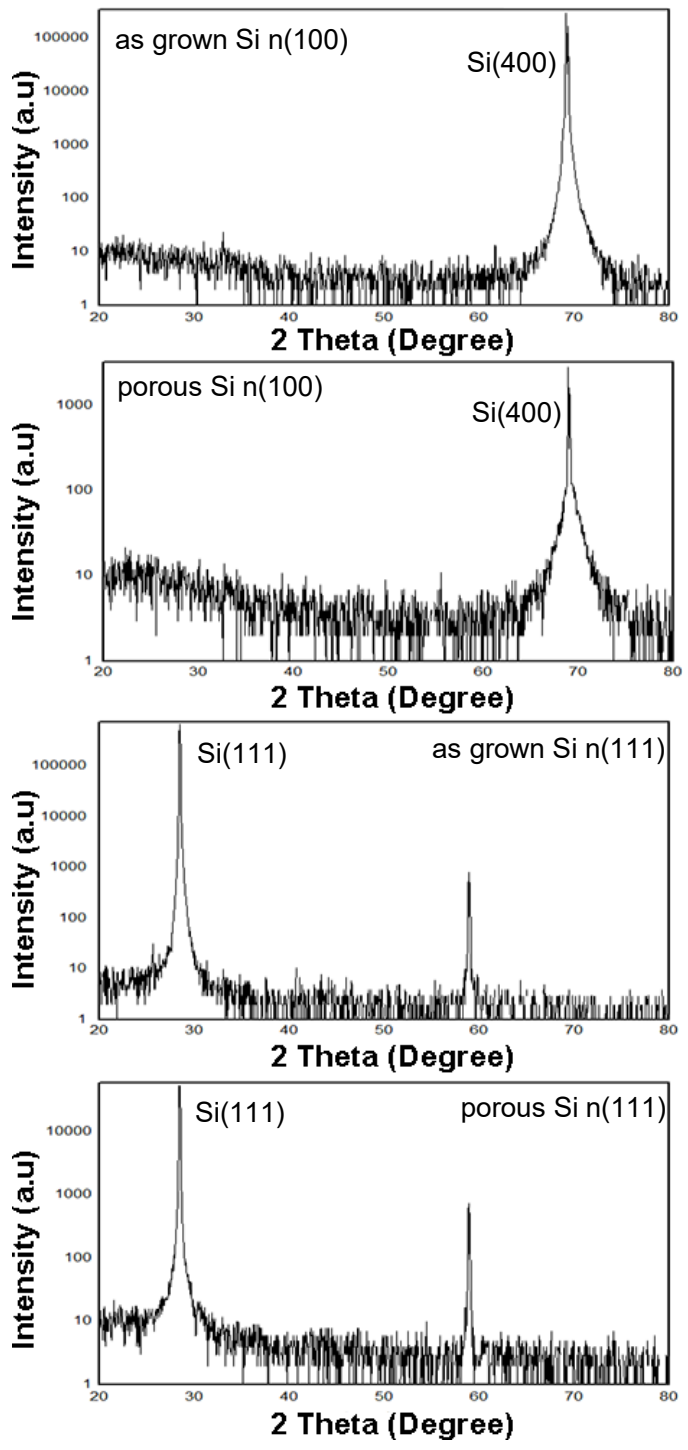

Fig. 4. The HR-XRD of as grown and porous Si samples with different orientation.

TABLE III

SUMMARY OF DATA OBTAINED FROM HR-XRD MEASUREMENT

\begin{tabular}{|l|c|c|c|}
\hline \multicolumn{1}{|c|}{ Sample } & $2 \theta\left(^{\circ}\right)$ & FWHM $\left(^{\circ}\right)$ & $\begin{array}{c}\text { Crystallite Size } \\
(\mathrm{nm})\end{array}$ \\
\hline As grown Si n(100) & 69.125 & 0.11 & 91.58 \\
\hline Porous Si n(100) & 69.175 & 0.10 & 100.76 \\
\hline As grown Si n(111) & 28.475 & 0.14 & 61.12 \\
\hline Porous Si n(111) & 28.425 & 0.16 & 53.48 \\
\hline
\end{tabular}




\section{High Resolution X-Ray Diffraction Analysis}

Fig. 4 shows the HR-XRD measurement of as grown and porous Si samples with different orientation. Results obtained from HR-XRD measurement can be used to evaluate the crystalline properties of the samples.

From Figure 4, the peak position for as grown $\mathrm{Si} \mathrm{n}(100)$ and porous Si n(100) occurred at about $69.1^{\circ}$ represented by (400) reflection of cubic Si phase. There was no peak shift occurred between porous $\mathrm{Si} \mathrm{n}(100)$ and as grown $\mathrm{Si} \mathrm{n}(100)$ which indicate no stress was experienced during the etching process [15]. In addition, the peak intensity for porous $\mathrm{Si} n(100)$ is lower compared to as grown $\mathrm{Si} \mathrm{n}(100)$. This is probably due to the formation of pores which influenced by the etching process [22]. Similar result could be observed from previous research work where the peak intensity for porous Si n(100) was lower than the as grown Si n(100) [23]. For as grown Si n(111) and porous $\mathrm{Si} \mathrm{n}(111)$, the peaks appeared at about $28.4^{\circ}$ which indicate the presence of cubic Si phase by (111) reflections. Similar trend has been observed for Si n(111) samples in which there were no peak shift and lower peak intensity of porous $\mathrm{Si}$ $\mathrm{n}(111)$ compared to as grown $\mathrm{Si} \mathrm{n}(111)$. This result is similar to some previous research where the peak intensity for porous $\mathrm{Si}$ $\mathrm{n}(111)$ was lower than the as grown $\mathrm{Si} \mathrm{n}(111)$ [14, 22]. Therefore, the formation of pores do not change the peak position of the samples. Table III tabulates the peak position, FWHM and the crystallite sizes of all the samples.

The average crystallite size of the samples can be obtained by using the Debye-Scherrer equation (1) as shown below:

$$
D=\frac{0.9 \lambda}{\beta \cos \theta}
$$

where $\mathrm{D}$ is the average crystallite size, $\lambda$ is the $\mathrm{X}$-Ray wavelength $(0.15406 \mathrm{~nm}), \beta$ is the FWHM in radians, and the $\theta$ is the diffraction angle in radians. From Table 3, the FullWidth-Half-Maximum (FWHM) value for porous Si n(100) is narrower compared to as grown $\mathrm{Si} \mathrm{n}(100)$ with average crystallite size of $\sim 100.76 \mathrm{~nm}$. The lower value of FWHM indicated better crystalline quality due to the uniform pores formation of porous Si n(100) compared to as grown Si n(100) [17]. Similar result could be observed in research by [23] where porous Si n(100) has lower FWHM value and larger crystallite size. Meanwhile, porous Si n(111) has higher FWHM value which resulted with lower crystallite size value of $\sim 53.48 \mathrm{~nm}$ compared to as grown $\mathrm{Sin}$ (111). A possible explanation for this was the formation of a few irregular pores with small diameter that were widely spread on the surface of porous $\mathrm{Sin}$ (111). The increase in FWHM value is probably due to the growth of native oxide on the surface of porous Si n(111) [17]. This result is in line with the result obtained by [14] that showed smaller crystallite size of porous Si n(111) compared to as grown Si $\mathrm{n}(111)$. From this result, different crystal orientation of $\mathrm{Si}$ resulted in different surface morphology.

\section{CONCLUSIONS}

Porous Si was successfully fabricated by using two-step ACPEC etching technique for different crystal orientation of $\mathrm{Si}$ substrate, namely $\mathrm{n}(100)$ and $\mathrm{n}(111)$. Based on results shown by FESEM, porous Si n(100) produced a higher density of pores and porosity percentage compared to porous Si n(111). Resultsfrom AFM also supported the data from FESEM as porous Si n(100) has higher surface roughness in RMS value and higher average pore depth compared to porous $\mathrm{Si} n(111)$. HR-XRD results showed that there was improvement in crystalline quality for porous Si n(100). In conclusion, based on all the dataobtained, porous $\mathrm{Si} \mathrm{n}(100)$ was more suitable to be used to fabricate porous sample as it formed higher density of pores with higher average pore depth than porous $\mathrm{Si} \mathrm{n}(111)$. The crystalline quality for porous $\mathrm{Sin}(100)$ sample was also improved after the etching process.

\section{ACKNOWLEDGMENT}

Authors would like to acknowledge the support from Universiti Teknologi MARA (UiTM) and INOR lab staff of Universiti Sains Malaysia (USM) in completing this research. The financial support from Ministry of Higher Education Malaysia (MOHE) through Fundamental Research Grant Scheme (600-RMI/FRGS 5/5(0107/2016) is gratefully acknowledged.

\section{REFERENCES}

[1] Y. Shishkin, Y. Ke, R. P. Devaty, and W. Choyke, A Short Synopsis of the Current Status of Porous SiC and GaN, vol. 483-485, 2005.

[2] L. Canham, Canham, L. T. Silicon quantum wire array fabricaiton by electrochemical dissolution of wafers. Appl. Phys. Lett. 57,

1046-1048 vol. 57, 1990.

[3] H. Hartono, C. Soh, S.-J. Chua, and E. A. Fitzgerald, "Fabrication and characterization of nano-porous $\mathrm{GaN}$ template for strain relaxed $\mathrm{GaN}$ growth," Physica Status Solidi (b), vol. 244, pp. 1793-1796, 2007.

[4] H. R. Abd, Y. Al-Douri, N. M. Ahmed, and U. Hashim, "Alternativecurrent electrochemical etching of uniform porous silicon for photodetector applications," Int. J. Electrochem. Sci, vol. 8, pp. 1146111473, 2013.

[5] R. Radzali, M. Z. Zakariah, A. Mahmood, A. F. A. Rahim, Z. Hassan, and Y. Yusof, "The effect of ecthing duration on structural properties of porous Si fabricated by a new two-steps alternating current photo-assisted electrochemical etching (ACPEC) technique for MSM photodetector," in AIP Conference Proceedings, 2017, p. 020003.

[6] N. Naderi, M. R. Hashim, and T. S. T. Amran, "Enhanced physical properties of porous silicon for improved hydrogen gas sensing," Superlattices and Microstructures, vol. 51, pp. 626-634, 2012/05/01/ 2012.

[7] A. Ramizy, Z. Hassan, and K. Omar, "Porous GaN on $\mathrm{Si}(111)$ and its application to hydrogen gas sensor," Sensors and Actuators B: Chemical, vol. 155, pp. 699-708, 2011/07/20/2011.

[8] K. Omar and K. A. Salman, "Effects of Electrochemical Etching Time on the Performance of Porous Silicon Solar Cells on Crystalline n-Type (100) and (111)," Journal of Nano Research, vol. 46, pp. 45-56, 2017.

[9] Y. Al-Douri, N. Badi, and C. H. Voon, "Etching time effect on optical properties of porous silicon for solar cells fabrication," Optik International Journal for Light and Electron Optics, vol. 147, pp. 343$349,2017 / 10 / 01 / 2017$.

[10] E. Chen, "III. Wet and Dry Etching," Apr, vol. 12, pp. 1-18, 2004.

[11] J. H. Duaa, M. H. J. Alzubaidy, and A. N. Abd, "Fabrication and Characterization of Porous Silicon," World Scientific News, vol. 94, pp. 321-328, 2018. 
[12] R. Radzali, N. Zainal, F. K. Yam, and Z. Hassan, "Porous In0.47Ga0.53N Prepared by KOH Electrochemical Etching with Different Light Source," Microelectronic Engineering, vol. 126, pp. 107-112, 2014.

[13] R. Radzali, Z. Hassan, N. Zainal, and F. K. Yam, "Structural and Optical Characteristics of Porous InAlGaN Prepared by Photoelectrochemical Etching," Journal of Alloys and Compounds, vol. 622, pp. 565-571, 2015.

[14] A. F. Abd Rahim, A. A. Mustakim, N. S. Mohd Razali, A. Mahmood, R. Radzali, A. S. Zoolfakar, and Y. Mohd Ali, "Crystal Orientation Dependance of Alternating Cureent Photo-assisted (ACPEC) Porous Silicon for Potential Optoelectronic Application," Microelectronics International, vol. 37, pp. 46-53, 2020.

[15] A. F. Abd Rahim, M. S. Abdullah, A. Mahmood, N. K. Ali, and M. Mohamed Zahidi, "Quantum Confinement of Integrated Pulse Electrochemical Etching of Porous Silicon for Metal Semiconductor Metal Photodetector," Materials Science Forum, vol. 846, pp. 245-255, 2016.

[16] J. Jakubowicz, "Nanoporous silicon fabricated at different illumination and electrochemical conditions," Superlattices and Microstructures, vol. 41, pp. 205-215, 2007.

[17] R. Radzali, M. A. Mohamed Azhar, A. Mahmood, F. Zulkifli, A. F. Abd Rahim and A. Abu Bakar, "Properties of Porous Silicon by Two-Step Alternating Current Photo-Assisted Electrochemical Etching (ACPEC) Technique under Different Applied Current Density for MSM Photodetector Device Application," ASM Science Journal, vol. 14, pp. 135-142, 2021

[18] N. H. Abd Wahab, A. F. Abd Rahim, F. I. Mohamad Latar, and A. Mahmood, "Investigation on the effect of crystal orientation dependence of pulse porous silicon for white light emission," in Key Engineering Materials, 2016, pp. 164-176.

[19] G. D. Sulka, "Highly ordered anodic porous alumina formation by selforganized anodizing," Nanostructured materials in electrochemistry, vol. 1, pp. 1-116, 2008.

[20] W. Chen, Y. Liu, L. Yang, J. Wu, Q. Chen, Y. Zhao, et al., "Difference in anisotropic etching characteristics of alkaline and copper based acid solutions for single-crystalline Si," Scientific reports, vol. 8, pp. 1-8, 2018.

[21] M. Aslam, "Bulk etching of silicon wafer and development of a polyimide membrane," in Journal of physics: conference series, 2013, p. 012029 .

[22] S. Sohimee, Z. Hassan, N. M. Ahmed, R. Radzali, H. Quah, and W. Lim, "Comparative Studies between Porous Silicon and Porous P-Type Gallium Nitride Prepared Using Alternating Current Photo-Assisted Electrochemical Etching Technique," in Journal of Physics: Conference Series, 2020, p. 012044.

[23] N. H. Abd Wahab, A. F. Abd Rahim, A. Mahmood, S. H. Mohmad Salleh, R. Radzali and Y. Yusof, "Structural Characterization on Different Type of Silicon Wafer on The Formation of Porous Silicon Structure," Journal of Physics: Conference Series, vol. 1535, 2020.

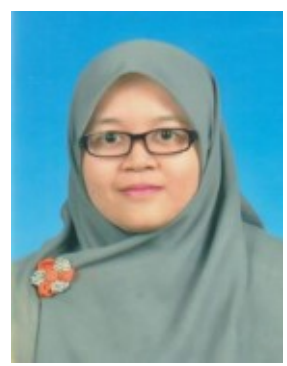

Fatimah Zulkifli obtained her B.Eng Hons in Electronics Engineering program under Faculty of Electrical Engineering, UiTM, Shah Alam. Currently, she is undertaking Msc. study at UiTM Pulau Pinang. Her research interests are in fabrication and characterization of porous structure for application in semiconductor devices.

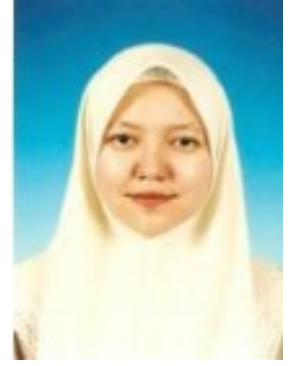

Rosfariza Radzali obtained her B.Eng in Electronics and System from Takushoku University, Japan and MSc. in Microelectronics from Universiti Kebangsaan Malaysia. She obtained her PhD from Universiti Sains Malaysia in Semiconductor Fabrication. Her research interests are in nanostructure fabrication and characterization of III-Nitrides (GaN, InGaN, InAlGaN) and silicon semiconductor for application in sensing devices such as gas sensors, photodetectors. On top of that, she is also interested in modelling and simulation of semiconductor devices using Silvaco TCAD Tools. She is currently a senior lecturer at Faculty of Electrical Engineering, Universiti Teknologi MARA, Malaysia.

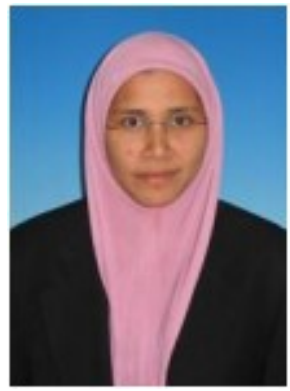

Alhan Farhanah Abd Rahim obtained her B.Eng Hons in Electronics Engineering from University of Southampton in 1998, MSc and PhD in Solid State Physics from Universiti Sains Malaysia in 2003 and 2014 respectively. She is currently senior lecturer at the Faculty of Electrical Engineering, Universiti Teknologi MARA, Malaysia. Her research interest are in synthesizing and fabricating advance semiconductor materials ( $\mathrm{Si}, \mathrm{Ge}, \mathrm{GaN}$ ) and devices utilizing low cost techniques. She is author and coauthor of over 40 scientific publications in this field.

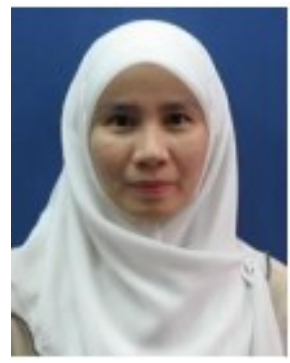

Ainorkhilah Mahmood obtained her B.Sc Hons in Applied Physics, M.Sc in Solid State Physics and PhD in Semiconductor Devices from Universiti Sains Malaysia. Her research interests are in Semiconductor Devices, Nanostructure's fabrication (III-Nitrides and Silicon), Photonics and optoelectronic application, photodetectors and gas sensor. She is currently working as a senior lecturer at Department of Applied Sciences, Universiti Teknologi MARA, Pulau Pinang.

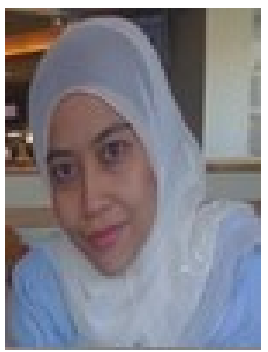

Aslina Abu Bakar obtained her $\mathrm{PhD}$ in Electrical Engineering from University of Queensland in 2012. Her research interest includes Microwave Imaging, Wearable Antenna and UWB microwave imaging applications. Currently she is a senior lecturer at Universiti Teknologi MARA, Pulau Pinang. 